\section{Chromosomal localization of the zinc finger protein 15, Zfp15, on Mouse Chromosome 4}

\section{M.L. Roller, S.A. Camper}

Department of Human Genetics, The University of Michigan Medical School, Ann Arbor, Michigan 48109-0618, USA

Received: 28 November 1994 / Accepted: 13 December 1994

Species: Mouse

Locus name: Zinc finger protein 15

Locus symbol: Zfp15

Map position: Zfp15 is localized on mouse Chromosome (Chr) 4: centromere-D4Bir11-7.4 $\pm 2.7-Z$ fp15-1.1 \pm 1.1-D4Mit4-17.0 \pm

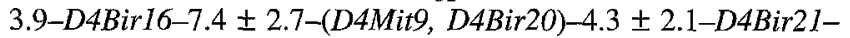

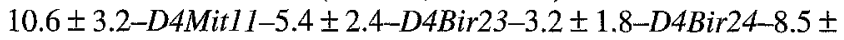
2.9-(D4Mit13, Pnd, D4Bir25, D4Mit14)-1.1 \pm 1.1-D4Mit42-6.4 $\pm 2.5-(D v l, R n r 4)$-telomere.

Method of mapping: Zfp15 was localized by haplotype analysis of 94 progeny from an interspecific backcross, $(\mathrm{C} 57 \mathrm{BL} / 6 \mathrm{~J} \times M$. spretus) $\mathrm{F}_{1} \times \mathrm{C} 57 \mathrm{BL} / 6 \mathrm{~J}[1]$.

Molecular reagents used for mapping: The Zfp15 probe was obtained by polymerase chain reaction amplification of a 552-bp fragment from mouse pituitary cDNA with primers designed on the basis of the rat Zfp15 cDNA sequence [2]. The primers amplify $465 \mathrm{bp}$ of coding sequence, outside of the conserved zinc finger regions, corresponding to the last 154 amino acids, and $87 \mathrm{bp}$ of the $3^{\prime}$ untranslated region. The RT-PCR product was cloned into the pGEM $4 Z$ vector and sequenced to confïm its correspondence with the rat $Z f p I 5$ cDNA.

Allele detection: A $B g l \mathrm{I}$ polymorphism was detected in mouse genomic DNA with the Zfp 15 probe, resulting in an $M$. spretusspecific restriction fragment of $15 \mathrm{~kb}$ and a common restriction fragment of $24 \mathrm{~kb}$. The mapping was confirmed with a BamHI polymorphism, resulting in two $M$. spretus-specific restriction fragments of 8.9 and $6.6 \mathrm{~kb}$ and two common fragments of 18 and $5.5 \mathrm{~kb}$.

Correspondence to: S.A. Camper

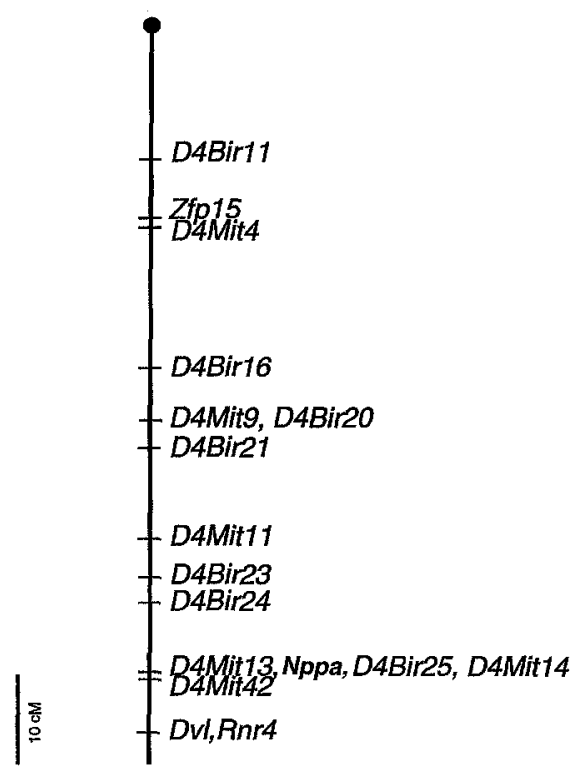

Chr 4

Fig. 1. Zfp15 maps on mouse Chr 4 proximal to D4Mit4.
Discussion: Zfp15, formerly called Zn-15, is a transcription factor that binds to a highly conserved DNA-binding site within the GH promoter between the proximal and distal Pit-1 binding sites. Its unique DNA-binding domain consists of three $\mathrm{CysX}_{2-4} \mathrm{Cys}_{11-16}$ His $_{3-6}$ His zinc fingers in the context of 15 highly conserved zinc fingers. It has been shown that Zfp15 acts synergistically with Pit-1 to activate the GH promoter. In contrast to Pit-1, Zfp15 shows no tissue specificity; it has been found in many tissues including pituitary, spleen, and heart [2]. There are no endocrine defects known in the region of Chr 4 where Zfp 15 is localized.

Acknowledgements: We thank The Jackson Laboratory for providing the backcross DNA. This work was supported by the National Institutes of Health grant NIH R01-HD30428 (S.A. Camper).

\section{References}

1. Rowe, L.B., Nadeau, J.H., Turner, R., Frankel, W.N., Letts, V.A., Eppig, J.T., Ko, M.S.H., Thurston, S.J., Birkenmeier, E.H. (1994). Maps from two interspecific backcross DNA panels available as a community genetic mapping resource. Mamm. Genome 5, 253-274.

2. Lipkin, S.M., Näär, A.M., Kalla, K.A., Sack, R.A., Rosenfeld, M.G. (1993). Identification of a novel zinc finger protein binding a conserved element critical for Pit-1-dependent growth hormone gene expression. Genes Dev. 7, 1674-1687.

\section{Localization of sequences related to the human RAD6 DNA repair gene on mouse Chromosomes 11 and 13}

\author{
M.L. Roller, ${ }^{1}$ A.C. Lossie, ${ }^{1}$ M.H.M. Koken, ${ }^{2}$ \\ E.M.E. Smit, ${ }^{2}$ A. Hagemeijer, ${ }^{2}$ S.A. Camper ${ }^{1}$ \\ ${ }^{1}$ Department of Human Genetics, The University of Michigan Medical \\ School, Ann Arbor, Michigan 48109-0618, USA \\ ${ }^{2}$ Department of Cell Biology and Genetics, Erasmus University, \\ Rotterdam, The Netherlands
}

Received: 28 November 1994 / Accepted: 13 December 1994

Species: Mouse

Locus name: Ubiquitin conjugation enzyme E2B-related sequences 1 and 2

Locus symbol: Ube2b-rs1, Ube2b-rs2

Map position: Ube2b-rs 1 is localized on mouse Chromosome (Chr) 13: centromere-D13Bir2-8.7 \pm 2.9-D13Bir4-3.2 $\pm 1.8-$ D13Mit4-11.8 $\pm 3.3-D 13$ Bir12-2.1 $\pm 1.5-$ D13Mit10-5.3 $\pm 2.3-$ D13Birl3-3.2 \pm 1.8-Dl3Birl4-7.4 $\pm 2.7-D 13 M i t 8-1.1 \pm 1.1-$ D13Mit9-4.4 \pm 2.1-D13Birl8-5.5 $\pm 2.4-D 13$ Birl9-9.9 $\pm 3.1-$ (D13Mit31, Ube2b-rs1)-1.1 $\pm 1.1-R n r 13$-telomere. Ube2b-rs 2 is localized on mouse Chr 11: centromere-Erbb-12.3 \pm 3.7-(Adral,

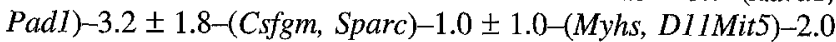

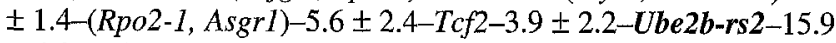
$\pm 4.0-E r b a-5.4 \pm 2.4-G h$-telomere.

Method of mapping: Ube $2 b-r s 1$ was localized by haplotype analysis of 91 progeny from an interspecific backcross, (C57BL/6J $\times$ $M$. spretus $) \mathrm{F}_{1} \times \mathrm{C} 57 \mathrm{BL} / 6 \mathrm{~J}$ [1]. Ube $2 b-r s 2$ was assigned by haplotype analysis of 96 progeny from an intraspecific backcross (DF/ B- $d f / d f \times \mathrm{CASA} / \mathrm{Rk}) \mathrm{F}_{1} \times \mathrm{DF} / \mathrm{B}-d f / d f[2]$.

Molecular reagents used for mapping: The mouse brain cDNA clone, MBL 12-900, is homologous to the human RAD6B gene (HHR6B). A 900-kb EcoRI fragment containing the complete open reading frame was used for mapping. This is referred to as the Hhr6b probe [3].

Allele detection: In mapping Ube2b-rs1, a BamHI polymorphism was detected in mouse genomic DNA hybridized with the Hhr6b

Correspondence to: S.A. Camper 